\title{
In-Sourcing or Outsourcing: An Economic Analysis on Internal and External Alternatives for Enterprise R\&D
}

\author{
Xiaoqi Rao, Ming Dai \\ School of Economics, Jinan University, Guangzhou, China \\ Email: xiaoqi5626@163.com
}

Received 18 May 2016; accepted 26 June 2016; published 29 June 2016

Copyright (C) 2016 by authors and Scientific Research Publishing Inc.

This work is licensed under the Creative Commons Attribution International License (CC BY). http://creativecommons.org/licenses/by/4.0/

c) (i) Open Access

\begin{abstract}
This article will use the theories of comparative advantages, transaction costs, cost minimization or profit maximization, conducting a deep analysis of the internal and external alternatives for enterprise $R \& D$ with respect to in-sourcing or outsourcing by modeling from the point of view of microeconomics, according to the enterprises' own R\&D relative advantages and disadvantages, the scale of the transaction costs of product development. Based on that, this paper makes corresponding countermeasures and suggestions, in order to provide certain theoretical references for the internal and external alternatives for enterprise R\&D.
\end{abstract}

\section{Keywords}

Comparative Advantage, Transaction Costs, R\&D In-Sourcing, R\&D Outsourcing

\section{Introduction}

On the one hand, specialization not only improves labor productivity, but also obtains increasing returns of scale. Hence, our country started to vigorously promote independent innovation in recent years, encouraging the enterprises to master the core technology and participate in the international division of labor, so as to improve the status of the chain of international industrial division. On the other hand, the biggest concern for most enterprises will still be how to maximize profits at certain costs or minimize the costs with certain output. This means that not all enterprises would blindly seek independent production or innovation for obtaining certain intellectual property rights, instead, they would take the costs and profits into account comprehensively, that is, considering the costs and profits under the condition that they are able to realize independent innovation, while the transaction costs should be taken into account when they are not (Figure 1). 


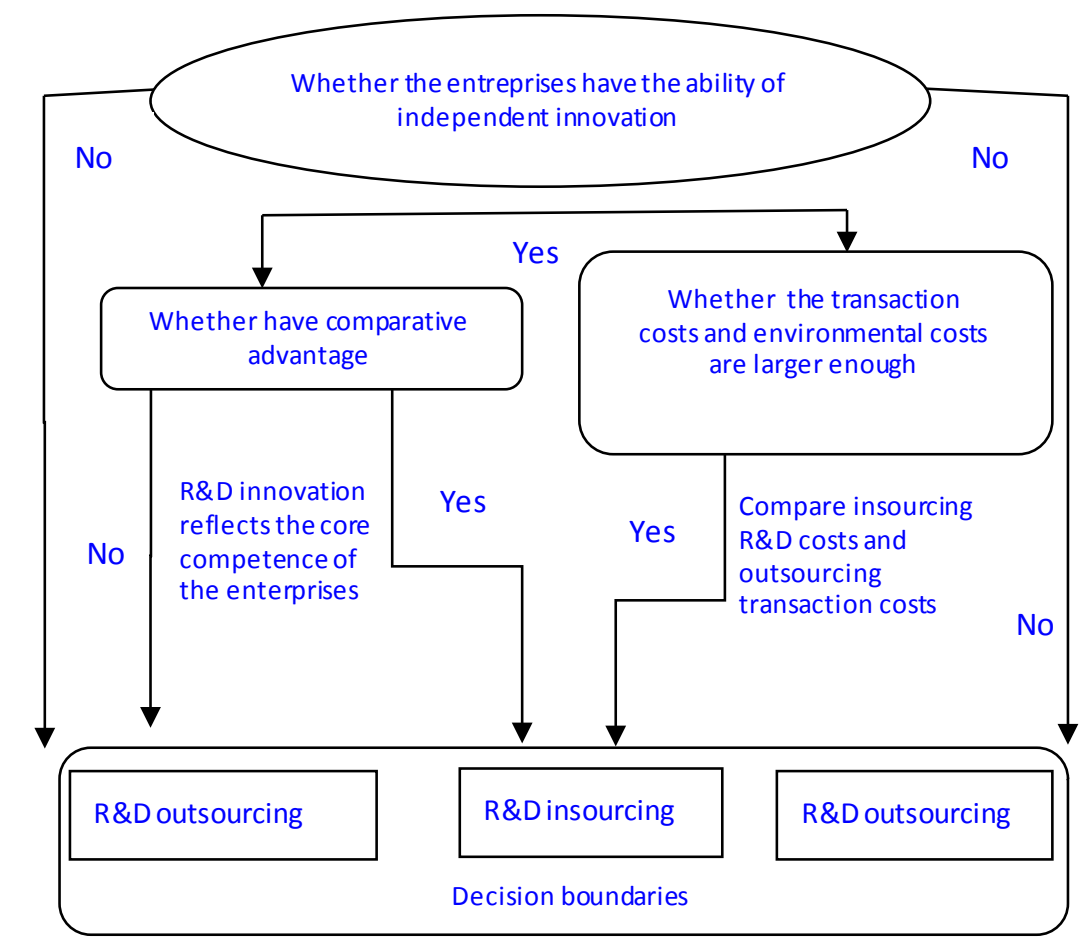

Figure 1. Logical reasoning analysis on the enterprise in-sourcing or outsourcing.

The enterprise endogenous growth theory proposed by Penrose argues that enterprises should internally carry out activities that have comparative advantages, while outsourcing those activities without comparative advantages [1]. According to Coase's theory with respect to the enterprises, if the costs of purchasing technology through the market are less than the costs of R\&D in-sourcing, the enterprises will purchase technology from the external markets, which will lead to separation of R\&D product trade or R\&D service from manufacturing enterprises. If knowledge integration costs of internal R\&D are greater than those of market, enterprises will purchase from external markets rather than by their internal training. "Positive effect" will be brought by specialization and scale as a result of R\&D outsourcing concentrating resources, but as a "vanguard" for the enterprises, $\mathrm{R} \& \mathrm{D}$ technology is a main form of output, especially, the "subsidiary knowledge products" produced in various stages of R\&D reflect the core competence of the enterprises. It is on the premise that either outsourcing or in-sourcing has its own advantages, that enterprises should seriously take R\&D into account, choosing their own appropriate development strategy path. Enterprise internal or external alternatives referring to R\&D issues are the key part of this study, and this article will make a detailed interpretation of the issue of the enterprise R\&D outsourcing or in-sourcing alternatives from the perspective of economics.

\section{Theoretical Basis}

\subsection{Theory of Comparative Advantage}

The theory of comparative advantage is a cornerstone of international trade. According to David Ricardo's explanation, the so-called comparative advantage theory refers to that certain economic activities of a country bring low-cost advantage through intensive use of its rich interior elements. For R\&D outsourcing, its capital intensity and sunk costs are lower, mainly the human resources costs. Due to the huge differences between the abundance and labor costs of human resources elements among economies at different levels, the effect of comparative advantage is most significant in the field of off shoring.

According to the literatures, Apte and Mason (1995) suggested that outsourcing could reduce costs, and its $\mathrm{R} \& \mathrm{D}$ cycle is short owing to a large number of skilled experts and huge developing markets. Ang and Straub (1998) found that the IT outsourcing had a positive correlation with the comparative advantage of production costs referring to outsourcing, and compared to the transaction costs, the production costs play a more important 
role in outsourcing decisions [2].

\subsection{Transaction Costs Theory}

The earliest theoretical study of economics on outsourcing is the new institutional economics mentioned in the transaction cost theory, which argues that outsourcing is actually a boundary enterprise problem. Coase (1937) believes that enterprise and market as two resources configurations are substitutability, and their choices depend on the comparison between market transaction costs and organization costs of internal enterprises, corporate boundaries should be located on the equilibrium point between the market transaction costs and internal organization costs of the enterprises [3]. Based on the theory put forward by Coase, Williamson (1979, 1985, 1996, 2000) expanded the transaction cost theory, mainly including study on the determinants of transaction costs and the socio-economic organization structure, and accordingly proposed the classic economic organization theory (transaction cost economics). For the factors that influence the transaction costs, he divided them into human factors, environmental factors and transaction market factors and other factors related to specific transactions. Human factors refer to "bounded rationality" and "opportunity behavior"; factors related to specific transactions refer to asset specificity, transaction uncertainty and trading frequency, which, as he called, the three dimensions of the transaction environmental factors and transaction market factors mainly refer to the market supply and demand, as well as the difficulty of market access to the extent impact the market prices. In terms of the socioeconomic organization structure, he believed that the market, enterprises, intermediate mixed forms and bureaucratic organizations are four different governance structures with different characteristics [4].

In the study of the impact of transaction costs on the outsourcing decisions, the majority of scholars regarded the three transactions dimensions as a starting point. Robertson and Gatignon (1998) suggested that the larger the technological uncertainty was the more likely companies would develop new technologies by the way of alliances rather than internal governance. Steensma and Corley (2002) found that there was a positive correlation between the opportunistic threats and the probability of enterprises choosing in-sourcing, and if the lower level of holding shares by the managers was, the opportunism-based transaction cost theory would explain the choice of enterprise boundaries better [5]. Barthelemy and Quelin (2006) also proved the impact of specific nature of the assets on outsourcing decisions through the empirical analysis on IT outsourcing in France and Germany, that is, the higher the specific assets is, the enterprises would prefer internal production; on the contrary, it would choose outsourcing [6].

\subsection{The Core Competence Theory}

C. K. Prahalad and G. Hamel (1990) published an article- “The Core Competence of the Corporation” in the "Harvard Business Review", formally proposing the core concept of enterprises competence, which means that enterprises have some incomparable capacities against other companies. Those capacities are organic combinations of multifaceted business skills and operational mechanism, as well as the principal resource consisted of competitive advantages for enterprises. The nature of the core competence theory is inimitable and alternative with valuable knowledge and resources, which is unique for the enterprises. To some extent, the core competence theory explains the rapid development of outsourcing industry. Since not all businesses that the enterprises involved have core competence, they would outsource those businesses without core competence through external sources (supplier sources) due to firms' source constraints. Enterprises use the limited internal resources for their core businesses, which is an inevitable requirement for the efficient allocation of resources, and the development of its own core competence.

Steensma and Corley (2002) pointed out that if the IT activities enable the competitive advantage to continue, then enterprises will choose the internal production strategy. Tomas and Victor (2005) believed that the enterprises could concentrate its limited resources on its core businesses after outsourcing their non-core businesses to external service providers, for the purpose of enhancing the core competence of enterprises. From the perspective of the core competence theory, in addition to those professional activities that give them the unique and competitive advantage (the core competence), rational enterprises would outsource their non-core businesses [5].

In terms of domestic aspects: first, the theoretical basis of service outsourcing. The theory of industrial division of labor proposed by Lu Feng is represented by domestic researches on the theoretical basis of service outsourcing. Lu Feng (2007) believed that the study on service outsourcing provided the framework of economic 
analysis based on the industrial division of labor. He pointed out that "despite the fact that service outsourcings is a microscopic behavior of decision-making for business management in a direct sense, such a generalization of the microscopic behaviors represent the changes of the overall production in a macro level, the concept of outsourcing involves all links of certain internal product and a particular form of segment division, and operations division develops over the world, which constitute an important microeconomic foundation of contemporary economic globalization [7]. M. A. Weihong \& Zhang Juan (2007) studied the mechanism of contemporary outsourcing from the perspective of product specialization by economics, finding that service outsourcing behavior was a product of product specialization in the service industry and the service processes of other industries after restructure and change [8]. Zhao Nan, Li Jing (2007) proposed that the service industry increasingly becomes a leading industry for international industrial transfer, and the service outsourcing including $\mathrm{R} \& \mathrm{D}$, has a strong desirability with the international transfer of the service industry [9].

The second is the motivation of service outsourcing development. Domestic scholars Li Zhiqiang and Li Zihui (2004) think that the inner core motivation prompting the multinational cooperation to outsource service over the world is the requirement for cost reduction [10]. Multinational corporations seek the lowest cost through outsourcing, chasing maximum profits. Chen Fei (2005) explained the motivation of service outsourcing from external environment motivation and internal driving force. The external motivation includes technical motivation (information technology and the development of the Internet), economic motivation (production, trade and the deepened financial globalization) and market motivation (intense market challenges); the internal driving force includes effective cost savings and improvement of the core competence [11]. Zhangfen Xia, Liu Jingjiang (2005) made a comprehensive analysis on the motivation of offshoring, pointing out that service outsourcing is the result of interaction among three factors, namely economy, technology and policy [12]. Yang Shengming (2006) proposes that the fierce competition in the industry is an external booster for the rise of outsourcing, which will reduce costs, while maximizing profit is the internal motivation for the rise of outsourcing development [13]. Zou Quansheng and Wang Ying (2006) analyzed the cost-benefit models in relation to the games at two stages based on the game theory. They argue that along with the ongoing economic and technological revolution, the integrated industrial model of traditional service industry will be replaced by the economic mode of production-outsourcing, and service industry would continue to evolve to a non-integrated model of service outsourcing [14].

\subsection{Definition of R\&D In-Sourcing and Outsourcing}

By definition, R\&D in-sourcing means enterprises or other research institutions retain the original self-development, but also refer to introducing the external projects for self-development and self-digestion. The so-called outsourcing means that enterprises or other organizations transfer the work doing on their own before to external vendors on the same premise of keeping the same final product set. And thus, those internal activities turn to external ones; if the objects transferred refers to manufacturing activities, such as the processing of a component or process, they are manufacturing outsourcing; if the objects transferred refers to service activities, such as financial accounting, security, cleaning and other activities, they are outsourcing; if the client and vendor are enterprises from different countries, it will be off shoring. R\&D mentioned in this article is one kind of service outsourcing. Whether in-sourcing or outsourcing, it depends on the enterprises. We should make a comprehensive decision combining with the comparative advantage, transaction costs and the core competence of enterprises.

\section{Modeling: An Economic Analysis on Enterprise R\&D Internal and External Alternatives}

\subsection{Modeling under Comparative Advantage and Transaction Costs of R\&D}

According to the theory of comparative advantage put forward by Li Jiatu, the changes are as follows, assuming the production rate of knowledge level for products $\mathrm{X}$ and $\mathrm{Y}$ of A company are $A_{x}$ and $A_{y}$, while that of $\mathrm{B}$ company are $B_{x}$ and $B_{y}$. If $\frac{A_{x}}{A_{y}} \geq \frac{B_{x}}{B_{y}}$, then A company has a comparative advantage in the knowledge level of $\mathrm{X}$ product, equally, B company has a comparative advantage in the knowledge level of Y product.

When translated into cost, assuming A company's product cost of product $\mathrm{X}$ and $\mathrm{Y}$ are $P_{x}^{A}$ and $P_{y}^{A}$, and $\mathrm{B}$ company's product cost of product $\mathrm{X}$ and $\mathrm{Y}$ are $P_{x}^{B}$ and $P_{y}^{B}$, and each cost is positive. According to the theory 
of comparative advantage, the necessary and sufficient conditions that "A company outsources the product development of $\mathrm{X}$ to $\mathrm{B}$ company” will be:

$$
\frac{P_{x}^{A}}{P_{y}^{A}}>\frac{P_{x}^{B}}{P_{y}^{B}}
$$

Considering the transaction costs and environmental costs, the total costs of R\&D will be the sum of all the three costs. If $i$ represents the vendor, $p$ represents the client, $T C^{i j}$ represents the total costs of the product development that the vendor $i$ received from the client $j . P_{j}^{i}$ represents the costs of product development that the vendor $i$ purchases from the client $j$, and $T_{p}^{i j}$ represents the transaction costs (for example, searching costs, product maintenance costs, training costs and of market transaction information) that the vendor $i$ purchases from the client $j, P_{j}^{i}$ and $T_{p}^{i j}$ are positive while $E_{p}^{i j}$ is negative. Learning from Deardorf's idea, we can obtain:

$$
T C^{i j}=P_{j}^{i}+T_{p}^{i j}+E_{p}^{i j}=P_{j}^{i}\left(1+\frac{T_{p}^{i j}}{P_{j}^{i}}+\frac{E_{p}^{i j}}{P_{j}^{i}}\right)=P_{j}^{i}\left(1+t_{p}^{i j}+e_{p}^{i j}\right)
$$

where $=$ represents the ratio of transaction costs and product development costs that the vendor $i$ purchases the products from the client $j \geq 0$ ) indicates the ratio of environmental costs and R\&D costs that the vendor $i$ purchases the products from the client $j$.

Therefore, after the introduction of transaction costs and environmental costs, due to the comparative advantage, the conditions that A company outsources x product to B company will be:

$$
\frac{P_{x}^{A}+T_{x}^{A B}+E_{x}^{A}}{P_{y}^{A}+T_{y}^{A B}+E_{y}^{A}}>\frac{P_{x}^{B}+T_{x}^{B A}+E_{x}^{B}}{P_{y}^{B}+T_{y}^{B A}+E_{y}^{B}} .
$$

Among them, the left side of the above formula represents the total production costs of A company's product $\mathrm{X}$ relative to $\mathrm{Y}$, while the right side of the above formula represents the total production costs of $\mathrm{B}$ company ' $\mathrm{s}$ product $\mathrm{X}$ relative to $\mathrm{Y}$.

When further optimizing the formula (2), we will obtain formula (3) as follows:

$$
\frac{P_{x}^{A}\left(1+t_{x}^{A B}+e_{x}^{A}\right)}{P_{y}^{A}\left(1+t_{y}^{A B}+e_{y}^{A}\right)}>\frac{P_{x}^{B}\left(1+t_{x}^{B A}+e_{x}^{B}\right)}{P_{y}^{B}\left(1+t_{y}^{B A}+e_{y}^{B}\right)} .
$$

If the result meets the formula (1), A and B enterprises would reconsider according to the comparative advantage of the total costs, due to the impact of transaction costs and environmental costs on R\&D comparative advantage of enterprises.

Combining Equation (4) and Equation (1), we will obtain the result of enterprise R\&D in-sourcing and outsourcing alternatives.

First, if $\frac{P_{x}^{A}\left(1+t_{x}^{A B}+e_{x}^{A}\right)}{P_{y}^{A}\left(1+t_{y}^{A B}+e_{y}^{A}\right)}>\frac{P_{x}^{B}\left(1+t_{x}^{B A}+e_{x}^{B}\right)}{P_{y}^{B}\left(1+t_{y}^{B A}+e_{y}^{B}\right)}$, A company will tend to outsource product $\mathrm{X}$ for R\&D, then focus on the R\&D of product $\mathrm{Y}$; B company will tend to reach and in-source product $\mathrm{X}$, while outsourcing product $\mathrm{Y}$.

Second, if $\frac{P_{x}^{A}\left(1+t_{x}^{A B}+e_{x}^{A}\right)}{P_{y}^{A}\left(1+t_{y}^{A B}+e_{y}^{A}\right)}<\frac{P_{x}^{B}\left(1+t_{x}^{B A}+e_{x}^{B}\right)}{P_{y}^{B}\left(1+t_{y}^{B A}+e_{y}^{B}\right)}$, then we need to make a further discussion based on it.

If $\frac{P_{x}^{A}\left(1+t_{x}^{A B}+e_{x}^{A}\right)}{P_{y}^{A}\left(1+t_{y}^{A B}+e_{y}^{A}\right)} / \frac{P_{x}^{B}\left(1+t_{x}^{B A}+e_{x}^{B}\right)}{P_{y}^{B}\left(1+t_{y}^{B A}+e_{y}^{B}\right)}>\frac{P_{x}^{A}}{P_{y}^{A}} / \frac{P_{x}^{B}}{P_{y}^{B}}$, then maintain the same enterprise R\&D in-sourcing and outsourcing alternatives. Synthetically considering the comparative advantages and relative total R\&D cost, A company will still tend to outsource $\mathrm{R} \& \mathrm{D}$ of product $\mathrm{X}$, and in-source $\mathrm{R} \& \mathrm{D}$ of product $\mathrm{Y}$; B company will tend to insource product $\mathrm{X}$, while outsourcing R\&D of product $\mathrm{Y}$. If

$\frac{P_{x}^{A}\left(1+t_{x}^{A B}+e_{x}^{A}\right)}{P_{y}^{A}\left(1+t_{y}^{A B}+e_{y}^{A}\right)} / \frac{P_{x}^{B}\left(1+t_{x}^{B A}+e_{x}^{B}\right)}{P_{y}^{B}\left(1+t_{y}^{B A}+e_{y}^{B}\right)}<\frac{P_{x}^{A}}{P_{y}^{A}} / \frac{P_{x}^{B}}{P_{y}^{B}}$, the strategy of A and B companies in relation to enterprise 
$\mathrm{R} \& \mathrm{D}$ in-sourcing and outsourcing alternatives will be reversed.

If $\frac{P_{x}^{A}\left(1+t_{x}^{A B}+e_{x}^{A}\right)}{P_{y}^{A}\left(1+t_{y}^{A B}+e_{y}^{A}\right)} / \frac{P_{x}^{B}\left(1+t_{x}^{B A}+e_{x}^{B}\right)}{P_{y}^{B}\left(1+t_{y}^{B A}+e_{y}^{B}\right)}=\frac{P_{x}^{A}}{P_{y}^{A}} / \frac{P_{x}^{B}}{P_{y}^{B}}$, then A and B two companies will have no comparative advantages in the development of products $\mathrm{X}$ and $\mathrm{Y}$, and the effects of in-sourcing or outsourcing will be the same.

Hereto, this article will supplement enterprise $R \& D$ in-sourcing and outsourcing alternatives referring to that how to maximize profits at certain costs or minimize the costs with certain output from the perspective of enterprises themselves.

\subsection{Modeling under the Conditions of Profit Maximization or Cost Minimization}

In accordance with the microeconomics theory of production: the optimal element combinations of production are minimum costs under a given production condition, the maximum production under a given cost condition. That is, enterprises need to minimize costs as well as maximizing returns for the purpose of maximizing profits. Corporate decision-making will first be constrained by the "cost-revenue", reducing the production costs is a basic means for enterprises to pursue scale interests. However, if the enterprise scale is too large, the organization costs of the enterprises will be too higher, and may even lead to "organizational failures", as well as decreasing scale. Driven by comparative advantage, outsourcing is an important way for enterprises to avoid reducing scale. Assume R\&D costs remain constant, the marginal benefit brought by in-sourcing and outsourcing for enterprises should be considered; if R\&D profit remains constant, then we should compare in-sourcing with outsourcing (Figure 2).

This article learns from the measure forms of components of transaction costs under the environmental policy [6], and makes some changes, then obtains the transaction fee constitutes of certain technology:

Assume $P_{o}$ is the external R\&D cost, $P_{i}$ is the internal R\&D cost that is R\&D budget. And $M P_{o}$ is the marginal revenue of external $\mathrm{R} \& \mathrm{D}, M P_{i}$ is the marginal revenue of internal $\mathrm{R} \& \mathrm{D}$ that is $\mathrm{R} \& \mathrm{D}$ revenue, either of which will add values for R\&D of enterprises.

Where,

$$
P_{o}=\sum_{i=0}^{T} R_{i t}+E_{i t}(c, k, \varepsilon)+D_{i t} .
$$

In formula (1), $i$ represents different technologies, $t$ represents the time, $R$ represents the cost of market searching, and $E$ represents the fees that paid to technology licensor directly for purchasing technology. And direct expenditures for purchasing technology consist of three parts: $c$ is the sum of each element of the technology transferred to the enterprises for technology R\&D, $k$ is maintenance cost of output technology-costs of in-

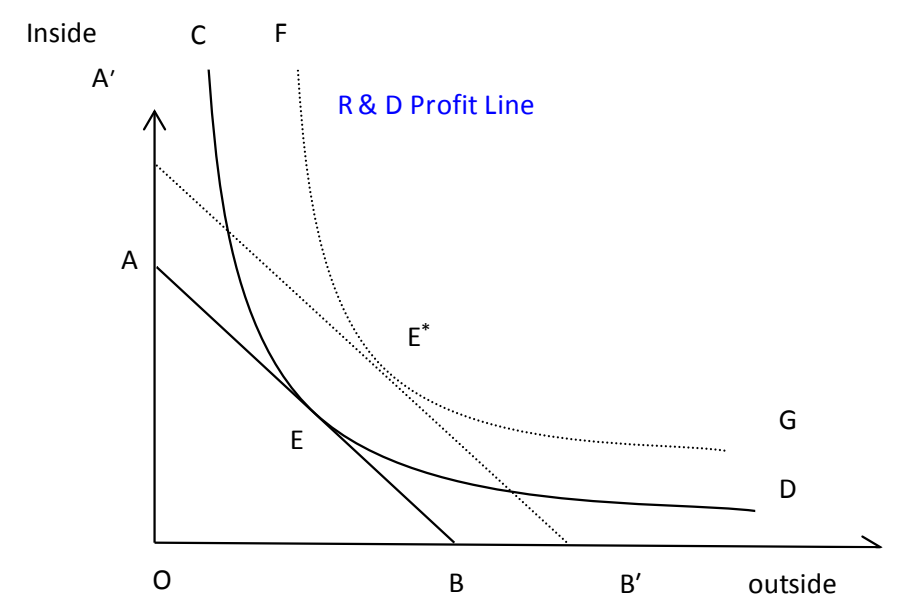

Figure 2. The cost-revenue analysis on R\&D internal and external alternatives. Note: $A B$ and $A^{\prime} B^{\prime}$ represent $R \& D$ profit line, $C D$ and FG represent $R \& D$ profit line, $E$ and $\mathrm{E}^{*}$ represent equilibrium point. 
tellectual property protection, $\varepsilon$ is an added value for product development, $D$ is technical management costs for the post-investment, including the cost of knowledge transferring and digesting, absorbing and using.

$$
P_{i}=\sum_{i=0}^{T} \alpha_{1}\left(S_{i t}+P_{i t}+M_{i t}+C\right) .
$$

In formula (2), $X_{i j}$ is the technical risk factor, $S$ is the costs of R\&D manpower, $P$ is the input costs of R\&D testing equipment and other hardware, $M$ is the maintenance costs for daily operation of internal R\&D institutions, $C$ is the maintenance costs of intellectual property after the success of technology R\&D.

$$
M P=W_{1}-W_{0}
$$

where $W_{1}$ is the current annual profit of enterprise (with the new technology support), $W_{0}$ is the annual profit of enterprise supported by the prior technology. According to the relationship of $\frac{M P_{o}}{P_{o}}$ and $\frac{M P_{i}}{P_{i}}$.

When $\frac{M P_{o}}{P_{o}}>\frac{M P_{i}}{P_{i}}$, it means the revenues of R\&D outsourcing are higher than R\&D in-sourcing at constant R\&D costs; or the costs of R\&D outsourcing are less than R\&D in-sourcing with constant R\&D revenue; that is, the DEB area in Figure 2 means enterprises will choose R\&D outsourcing.

When $\frac{M P_{o}}{P_{o}}<\frac{M P_{i}}{P_{i}}$, it means the revenues of R\&D outsourcing are less than R\&D in-sourcing at constant $R \& D$ costs; or the costs of $R \& D$ outsourcing are higher than $R \& D$ in-sourcing with constant $R \& D$ revenue; that is, the AEC area in Figure 2 means enterprises will choose R\&D insourcing.

We might make a conclusion that: AEC is the R\&D in-sourcing area, BED is R\&D outsourcing area; with the increasing investment for $R \& D, R \& D$ revenues will also be increased, and enterprises might still comply with this criteria to select in-sourcing or outsourcing; the decision-making region will be divided into R\&D insourcing region $A * E * F$, and the outsourcing decision-making region $B * E * G$.

\subsection{Further Analysis on "Cost-Revenue" under the Conditions of R\&D Outsourcing Decision-Making}

Considering the improvement of the core competence, under the premise of limited in-sourcing ability referring to $R \& D$, or overstated in-sourcing costs, the $R \& D$ outsourcing will promote the development of enterprises in two aspects: first, reduce the enterprise-level system, and optimize enterprise organizational structure, reducing the internal operating costs of organization due to the vertical integration business, so as to reduce the transaction costs of enterprises to some extent; second, enterprises can focus on enhancing the core business ability, raising the technical level and improving production efficiency, as well as reducing the production costs, which will be helpful for reducing the total costs and improving the overall efficiency (Figure 3). Combined these two factors, the total marginal costs of R\&D outsourcing will be reduced, resulting in that curve $\mathrm{MC}_{1}$ moves to

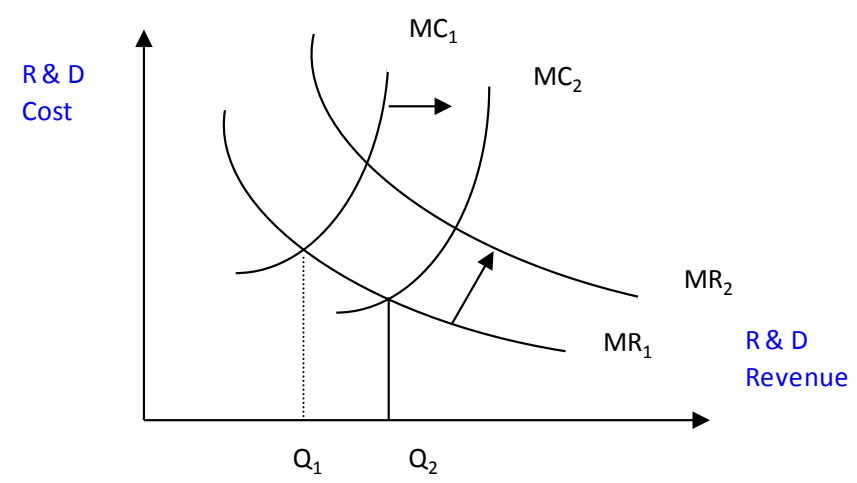

Figure 3. The "cost-revenue" analysis on the service outsourcing decision-making. 
$\mathrm{MC}_{2}$. According to the principle that marginal revenue is equal to marginal cost in the theory of microeconomics production, the balanced production of enterprises should be correspondingly increased from $\mathrm{Q}_{1}$ to $\mathrm{Q}_{2}$. In addition, with the technological progress of enterprises, enhancing the core competence of enterprises will contribute to improving their product quality and market influence, raising the marginal revenue of enterprises, that is, curve MR will move toward upper right, and thus further enhance the level of corporate earnings.

\section{Demonstration: Case Study}

\subsection{Geelyautomobile}

In November 1986, Geely was founded as a private small company producing refrigerator parts only; in 1989, it changed to produce high-grade decoration materials, developing the first magnalium crank plate made in China; in June 1994, it entered into the motorcycle industry, creating a first luxury scooter motorcycle in China; in 1997, it entered into the automotive industry, being the first Chinese private auto company; and in September 2005, it made its debut in the 61st Frankfurt Motor show, making a historic breakthrough for the China auto brand participating in the world's top auto show for nearly a century; in 2006, it received the invitation from the North American international auto show in Detroit again, making a first historic breakthrough for the North American auto show for 98 years in which the China autos first participate, abstracting hundreds of thousands people to visit Geely booth, which has aroused strong repercussions. Till March 2010, Geely chairman Li Shufu and Ford Chief Financial Officer Lewis Booth signed a definitive stock purchase agreement in Gothenburg, and Geely acquired $100 \%$ equity and related assets (including intellectual property) from Volvo Car Corporation.

The remarkable achievement is not only because of sizing up the situation with the capture of the times development to accomplish transition successfully, more importantly, it is derived from Geely's clear understanding of its own comparative advantage, and the spirit of focusing on independent R\&D as well as constant selfinnovation. In May 2007, “Geely-Tongji Automotive Engineering Research Institute” was founded, and in 2008, China's first master's doctoral programs of vehicles-Zhejiang College of Engineering were established, with complete capabilities of development of vehicle, engines, transmissions and automotive electronic appliances. Modeling design institutes have established in Shanghai, China, Sweden, Gothenburg, Barcelona, Spain, California, building global design system; set up CEVTs in Gothenburg and Sweden, building a globally competitive Chevrolet modular infrastructure. With the help of its more than 4700 engineering and technical personnel, three academicians, hundreds of foreign experts, more than 60 registered doctors, more than 800 masters as well as strong R\&D team constituted by hundreds of engineers and senior engineers, Geely has obtained more than 11,800 patents referring to different items, including more than 2100 invention patents, more than 40 international patents, being listed as "China top ten brands of intellectual property innovation", a national "enterprise technology center", "post-doctoral workstations" and "high-tech enterprises". "Technological innovation system construction of strategic transformation in Geely" has won the second award of National Science and Technology Progress (vacancy for the first prize); "the development and industrialization of Geely auto safety technology" won the first prize of China Automobile Industry Science and Technology.

It is under the premise of Geely's clear understanding of its comparative advantage of R\&D, Geely choose R\&D in-sourcing, achieved a scale development mode of R\&D marginal costs continuing to decrease and R\&D revenue increasing. Examples of Volvo Car Corporation 100\% equity and related assets acquired by Geely also confirms the disadvantages of Volvo Car Corporation-lack of comparative advantage in automobile production, high $R \& D$ costs and low revenue.

\subsection{Hisense Group}

Hisense Group was Qingdao Radio Plant before, producing transistor radios by only dozen people at the beginning, and then producing the 501-type transistor desktop radio. In August 1970, Qingdao Radio Plant II developed the first tube-type television 14 inches in Shandong Province, setting a precedent in Hisense's involvement in TV. By 2008, Hisense's first 42 inches ultra-thin LED backlit LCD TV TML42T08GP officially listed, declaring the arrival of the Chinese LED LCD TV era. In 1995, Hisense Technology Research Center (corporation) was set up, laying a solid foundation for the development model of industrial technology incubator; and in July 1995, Hisense Research Institute upgraded to National Technology Research Center. Then in 2000, Hisense officially launched the new VI system, proposing the corporate philosophy that "technology is the root, talent is the trunk, and innovation is the soul". 
In 2001, Hisense developed China's first color screen phone C2101. In 2002, Hisense acquired Beijing Snowflake refrigerator factory and found Hisense Hitachi Air Conditioning Systems Co. Ltd. with a joint venture with Japan's Hitachi. By 2005, China's leading independent intellectual property of industrial digital video processing chip-Hiview was born in Hisense, which means the history of Chinese color TV sets with annual output of 73 million using foreign chips is about to end. Premier Wen Jiabao highly appreciated Hisense for its good independent research and innovation tradition, and writing an inscription for it: "it's based on independent R\&D development and technological innovation, that the enterprises have vitality; it's because of the independent intellectual property rights and core technology, that the enterprises become competitive”. It is in that year, Kelon and Hisense signed a share transfer agreement, Hisense acquired Kelon with the final bid of 680 million Yuan. So far, Hisense has listed companies of Hisense and Kelon in Shanghai, Shenzhen, Hong Kong, and three wellknown trademarks of Hisense, Kelon, and Rongsheng.

From the point of view of Hisense innovation system, Hisense has owned seven R\&D centers, namely Qingdao R\&D Center Headquarters, Hisense R\&D Center in Shunde, Shenzhen R\&D Center, Canada R\&D Center, the US R\&D Center, European R\&D Center, the United States Fibre Communications R\&D Center, which have established relatively perfect platforms for research and innovation system, including the applied research center (key laboratory of digital multimedia technology for the state, etc.), product development center, industrial design center, user experience evaluation center, testing center, intellectual property management center, data center, exchange center of technical training and international cooperation, post-doctoral research station, etc., responsible for developing the core technology of industry and front-end technology, development of new products and industrial upgrading, as well as the product structure adjustment. There are more than 3,800 full-time R\&D personnel, including more than 80 senior experts and doctors, more than 1200 masters, more than $90 \%$ of R\&D staff are young people under 40 years old. Hisense pays attention to R\&D investment, its annual investment in scientific and technological activities accounts for more than $5 \%$ of sales revenues, which have created favorable conditions for the updating and development of knowledge of R\&D personnel. The annual training fees are almost tens of millions Yuan. Nearly a decade, the national science and technology projects for which Hisense are responsible are almost a hundred, wherein two 973 projects, seven 863 projects and six major science and technology projects; it hosted and participated in revision of 15 international standards and 225 national and industrial technology standards, which have been enacted nine international standards, 89 national and industry technical standards; total patent applications are nearly nine thousand, 2500 applications for invention patents included; national, provincial and municipal major science and technology awards 117. Hisense was named as the first "innovation-oriented enterprises" by China Science and Technology, SASAC and ACFTU.

From the current development of Hisense, we can see that sustained development of comparative advantage of Hisense has laid a foundation for Hisense's acquisition of Beijing Snowflake, Kelon and Rongsheng, which also reflects the comparative disadvantage of electric R\&D among snowflake refrigerator, Kelon and Rongsheng. And we still find that the revenues of Hisense R\&D keep rising while the marginal costs of R\&D reducing, and thus Hisense has become larger and larger, stronger and stronger, and Kelon and Rongsheng Electric also survive after being acquired.

\section{Relevant Recommendations of the R\&D Internal and External Alternatives}

With the rapid development of technological innovation at present, the uncertainty of R\&D in-sourcing or outsourcing will continue to increase. To some extent, it has become reality that gradual separation of R\&D from manufacturing industry. In the short term, in addition to their traditional comparative advantages, the total cost factors, including production costs, transaction and environmental costs should also be considered referring to the R\&D in-sourcing and outsourcing alternatives. Under certain conditions of natural resources, affected by transaction costs and environmental costs, the total costs might weaken or enhance their comparative advantage based on production costs, or it may reverse the comparative advantage of enterprises based on production costs. Regarding this, in order to make a clearer decision on the use of theoretical models of in-sourcing or outsourcing in relation to enterprise $\mathrm{R} \& \mathrm{D}$, this article proposes the following recommendations:

\subsection{Government Level}

First, pay attention to the construction of technical trading information platform, creating an efficient platform for technology or intellectual property transactions, fully sharing information between supply and demand to 
reduce market searching and transaction costs, improving transaction efficiency between enterprises. IPR Patent Pools are currently established in some areas, as well as technical trading exhibition, which are both specific forms for all technical trading platforms. Second, continue to encourage strong enterprises to improve their independent ability of R\&D, paying attention to the protection of intellectual property, and creating a good environment for protection of intellectual property. Raise the cost of intellectual property violations through government measures, protecting the interests of main R\&D, especially conceptual design, pilot, "intermediate product" produced during medium pilot in the development process, as well as property rights of knowledge, technology materialized value, piloting subsidies and incentives for key technologies, such as Geely and Hisense mentioned in this article, so that the whole social enterprises will be able to coordinate and share the R\&D interests.

\subsection{Industry Level}

First, the industrial clustering effect should come into play, building economyof scale and scope in R\&D industrial development. By building systems of regional research and innovation networks and technology innovation, reducing R\&D uncertainty and transaction costs, to guide enterprises with different R\&D capabilities forming networks system of labor division, and then achieve the regional industrial cluster development. Second, speed up industrial upgrading guided by the technology, promoting R\&D alliances and building open innovation network between enterprises, regions and the globe, doing some joint researches on key technology and the core technology to form a multi-level target system for technology R\&D with a number of specialized R\&D institutions, national laboratories, multinational enterprises R\&D center by expanding the flow of knowledge.

\subsection{Enterprise Level}

First, enterprises should have self-awareness, clarifying their own comparative advantages, and then making a full use of the opportunities that the social talent "dividend" brought. In the personnel recruitment system, accelerate the scale of the flow of talent through the promotion of labor market integration, improvement of equity, options, incentives and other measures. In the reserve of human resources, it gradual transits to innovative R\&D capabilities, and personnel management, so as to promote high-tech talent spatial concentration and knowledge diffusion, thereby reducing the cost of knowledge transfer, inspiring more companies to focus resources on the development of the value chain, core service areas, and enhancing their core competence.

\section{Funding}

Project source: Guangdong Key Soft Science Guide Project (2011B070300066); Guangdong Industry Development and Cooperative Research Center Project among Guangdong, Hong Kong, Macao and Taiwan-“R\&D industry Comparation and Collaborative Research of Cross-Strait and Guangdong-Taiwan” (52702481).

\section{References}

[1] Penrose, E. (2007) Enterprise Growth Theory. Joint Publishing, Shanghai People’s Publishing House, Shanghai.

[2] Ang and Straub (1998) Production and Transaction Economics and Its Outsourcing: A Study of the U.S. Banking Industry. MIS Quarterly, 12, 40-45.

[3] Coase, R.H. (1994) Production Systems and Structures (Chinese Version). Joint Publishing, Shanghai.

[4] Williamson (2002) Capitalist Economic System. Commercial Press, Beijing.

[5] North, D. (1994) Institutions, Institutional Change and Economic Performance (Chinese Version). Joint Publishing, Shanghai.

[6] Bathelemy, G. (2001) IT Outsourcing: Evidence from France and Germany. European Management Journal, 195.

[7] Feng, L. (2007) Economics Analysis on Service Outsourcing: The Perspective of Product Division. Peking University Press, Beijing.

[8] Weihong, M.A. and Zhang, J. (2007) Thought of Restriction Factors and Countermeasures of the Development of Service Outsourcing. Foreign Trade Practice, 58-60.

[9] Zhao, N. and Li, J. (2007) Path Selection of China's Development Outsourcing. Economists, 107-110.

[10] Li, Z.Q. and Li, Z.H. (2009) Current Development Trend and Countermeasures of Service Outsourcing. International 
Economic Cooperation, 15-18.

[11] Chen, F. (2005) Analysis on Outsourcing Driving Factors and Prediction of Future Development Trends. China Industrial Economy, 67-73.

[12] Zhang, F.X. and Liu, J.J. (2008) Review of Offshoring Development. Economic Issues, 24-26.

[13] Yang, S.M. (2008) Accelerate the Development of China's Service Outsourcing Industry. CASS Graduate School Journal, 18-25.

[14] Zou, Q.S. and Wang, Y. (2009) Service Outsourcing: Theoretical and Empirical Analysis. International Trade Issue, 54-61.

Submit or recommend next manuscript to SCIRP and we will provide best service for you:

Accepting pre-submission inquiries through Email, Facebook, Linkedin, Twitter, etc A wide selection of journals (inclusive of 9 subjects, more than 200 journals)

Providing a 24-hour high-quality service

User-friendly online submission system

Fair and swift peer-review system

Efficient typesetting and proofreading procedure

Display of the result of downloads and visits, as well as the number of cited articles

Maximum dissemination of your research work

Submit your manuscript at: http://papersubmission.scirp.org/ 